\title{
Exploring the Effect of Songs of Various Genres on Young Adults' Thoughts, Feelings and Actions
}

\author{
Ms Aheli Chakraborty ${ }^{1}$, Dr. Durgesh K. Upadhyay ${ }^{1}$, Prof. (Dr.) Manju Agrawal ${ }^{1}$
}

\section{ABSTRACT}

The purpose of this study was to find out whether songs (with lyrics) of various genres had any effect on the thoughts (cognitive), feelings (affective) and actions (conative) of young adults with varied personality traits. This study further examined which personality factor was more associated with thoughts, feelings and action tendencies generated through songs of various genres. A sample of 60 young adults (30 boys and 30 girls) of age group 18-27 years, pursuing graduation and post-graduation degrees from Amity University, Lucknow campus were selected. Tools used were Big Five Inventory (by John \& Srivastava) and a 4-point Cognitive, Affective and Conative (CAC) scale (developed by Authors). Findings provide insights about the significance of music as media in day-to-day lives of young adults, particularly on their cognition and the amount of affect based on their personality factors. The time phrase i.e. young adulthood, what has been called the most crucial age, needs to be exposed to such music which does not only prove to be a source for chills and enjoyment but also which fosters its well-being.

Keywords: Personality; Music Genres; Thoughts; Feelings; Actions.

Music is an inevitable part of everyone's life right from his/her childhood. Zentner and Eerola (2010) found that infants as young as five months old respond rhythmically to music and seem to find it more interesting than speech. Everyone feels the chills of music at least at some part of his/her life. Young adults, nowadays, more than any other age groups are exposed to various genres of music ranging from The Beatles, Pink Floyd, Eminem, Metallica to Bollywood Item Numbers as well as Sufi and Romantic pieces. Listening to music sometimes makes a person leave his seat and shake a leg whereas, some music pieces make someone cry his heart out. Some music pieces provide solace and an aura of transcendence whereas, some music pieces makes people gushy, happy and think about their romantic partners. Not everyone perceives a musical piece in the same way. A song may evoke a negative feeling in an individual whereas in some other individual it may evoke a happy feeling.

\footnotetext{
${ }^{1}$ Amity Institute of Behavioural and Allied Sciences, Amity University Uttar Pradesh, Lucknow

*Responding Author

(C) 2016 I A Chakraborty, D Upadhyay, M Agrawal; licensee IJIP. This is an Open Access Research distributed under the terms of the Creative Commons Attribution License (http://creativecommons.org/licenses/by/2.0), which permits unrestricted use, distribution, and reproduction in any Medium, provided the original work is properly cited.
} 
According to the General Aggression Model (Bushman \& Anderson, 2002), exposure to violent media (including song lyrics) leads to the activation of various internal states such as affect, cognition, physiological or cognitive arousal in an individual that led him/her to respond in an aggressive way. Song lyrics have the ability to influence behaviour and it was found out that male customers, and not female, exposed to romantic songs that were played in a flower shop spent more money on purchase rather when no music/romantic music were played (Jacob, Gueguen, Boulbry, \& Sami, 2009). The similar effects were found when people were exposed to songs having aggressive lyrics rather than neutral ones. On listening to these music pieces, aggressive behaviour, thoughts and feelings increased in the participants (Fischer \& Greitemeyer, 2006).

Music and actions are two simultaneous paradigms and it has been found out that music influences certain 'action tendencies' like helping other people, to buy certain products (Hargreaves \& North, 2010). Throughout history, music was composed to inspire people into specific action - to march, dance, sing or fight. Consequently, heightening the emotions in all these events. In fact, many people report being unable to sit still when certain rhythms are played, in some cases even engaging in subliminal actions when physical manifestations should be suppressed. Examples of this can be seen in young children's spontaneous outbursts into motion upon hearing music, or exuberant expressions shown at concerts (Sloboda \& Juslin, 2001).

Emotions are relatively brief, intense and rapidly changing reactions to potentially important events in the external/internal environment which involves a number of subcomponents (cognitive changes, subjective feelings, and expressive behaviour and action tendencies) that are more or less 'synchronized' during an emotional episode (Sloboda, 2011). Music listening often gives rise to expressive behaviour like crying, smiling, laughing and furrowing the eyebrows. Among all these, crying is the most common one, which is expressed after few seconds of listening to the music (Frey, 1985).

The emotions elicited by listening to different types of music seem to be affected by factors such as personality and previous musical training. People with the personality type of agreeableness have been found to have higher emotional responses to music in general. Stronger sad feelings have also associated with people with personality types of agreeableness and neuroticism (Rentfrow \& Gosling, 2007). Women in comparison to men are more likely to respond to music emotionally (Chamorro-Premuzic et al., 2009). Furthermore, females prefer popular music more than males (Rawlings \& Ciancarelli, 1997). In a study of personality and gender in preference for exaggerated bass in music, researchers found that males demonstrated more of a preference for bass music than females. This preference for bass music is also correlated with antisocial and borderline personalities (McCown et al., 1997). 
Juslin and Sloboda (2001) conducted a study in New York to find an answer to a pervasive belief that music can, at times, actually produce emotion in listeners. The distinction between production and perception is related to the distinction between cognitivism and emotivism proposed by philosophers in their analysis of emotion in music (e.g. Kivy, 1989). Whereas, 'emotivists' hold that music elicits real emotional responses in listeners, 'cognitivists' argue that music simply expresses or represents emotions. They formalized that music produces emotional effects in the listener that go beyond the cognitive inference of what the music can be said to express.

Peter Rentfrow, an assistant professor at the University of Cambridge, also thought that personality has much to do with music preferences. In a 2003 study called "The Do Re Mi's of Everyday Life: The Structure and Personality Correlates of Music Preferences,” he and Sam Gosling, a professor at the University of Texas at Austin, came up with four categories for music. These are Reflexive and Complex (blues/classical/folk/jazz), Energetic and Rhythmic (hip hop/dance), Upbeat and Conventional (religious/country/pop), and Intense and Rebellious (heavy metal/rock/alternative rock). They found that those who fell into one group over another had a few common characteristics. (a) Energetic and Rhythmic: confident, liberal-minded, gregarious, athletic, feels attractive; (b) Upbeat and Conventional: trusting, hardworking, feels attractive, helpful, and politically conservative; (c) Reflexive and Complex: open-minded, politically liberal, creative, intelligent, tolerant, enjoys aesthetic experiences; and (d) Intense and Rebellious: athletic, energetic, adventurous, intelligent, and inquisitive.

Chamorro-Premuzic and Furnham (2007) conducted a study on personality and uses of music using structural equation modelling. Responses from 227 Malaysian students to questionnaires showed that in line with hypotheses, individuals higher in Neuroticism were more likely to use music for emotional regulation; Extraversion positively predicted uses of music as background or for distraction and Openness to Experience predicted cognitive use of music. However, contrary to the target paper, Conscientiousness did not predict use of music for emotional regulation and extraversion was positively linked with that use of music. Results were discussed in terms of generalizability of previous findings on the Big Five as determinants of music.

Therefore, concluding from all the reviews of literature it was found out that people with personality type of agreeableness and neuroticism responded to music with higher emotional responses in general. People with Extraversion has a positive approach towards the use of music and people with Openness to Experience used music more cognitively. The studies are conducted on various parts of the world but not on an Indian population. Moreover, there is no correlation found between the genres and the personality types. Indian sample being culturally rich and musically sound, would serve as the new outlook towards the perception of music. People with different types of personality traits might not perceive music in the same way as the people of the other country does. 
Viewed against this backdrop, it has been hypothesized that music lyrics of various genres evoke certain thoughts, feeling and actions in its listeners; personality factors of listeners correlate with the amount of thoughts, feelings and action tendencies generated through music lyrics; and differences in ratings of thoughts, feelings and actions exist in terms of demographics (e.g., age, gender, level of education, etc.).

\section{METHOD}

\section{Respondents}

A sample of 60 young adults (30 boys and 30 girls) pursuing various degrees at both graduation and post-graduation levels from Amity University, Lucknow Campus had taken part in the survey. A pilot study on 28 participants was carried out before the finalisation of the rating scale. All the participants were of the age group 18-27 years $(M=20.42 y r s ; S D=2.12)$. The sample was drawn using Snowball Sampling Technique.

\section{Tools}

1. Big Five Inventory - John, O.P., \& Srivastava, S. (1999) constructed this 44 item inventory that measures an individual on the Big Five Factors (dimensions), namely, Openness to Experience; Conscientiousness; Extraversion; Agreeableness and Neuroticism of personality (Goldberg, 1993). Each of the factors is then further divided into personality facets. The reliability of the Inventory is 0.75 and the validity is convergent and quite high.

2. CAC Scale - This scale was constructed by authors to measure the Cognitive, Affective and Conative perceptions after listening to music pieces. Responses were initially recorded from the sample in the pilot study and based on those responses, the final rating sheet was constructed which is a 4-pointer scale.

\section{Procedure}

28 people participated in this study as a pilot group and they were made to listen to 20 songs (4 songs each from 5 genres) for a minute per song and were asked about the various thoughts, feelings and actions that were evoked on listening to these songs. These 5 genres were chosen among various other genres because of the practicability and feasibility issues and the genres were chosen by a panel of experts who have a rich taste of music. The researcher noted down all the responses that were given by them and based on the most popular responses a final rating sheet was constructed to measure the thoughts, feelings and actions after listening to the music pieces of varied genres.

Answers that were to be given by the respondents for the final study had to be rated according to the four pointer rating scale where, 1 = Not at All; 2 = somewhat; 3 = Much; 4 = Very Much. Before answering to the rating sheets, the 60 respondents of the final study had to fill in their demographic details, which included their age, gender, ethnic background, educational qualification, occupational status and music background. For assessing their personality, the 44item Big Five Inventory was used. The participants were asked to fill in the demographic details 
and the big five inventory first and then were presented with chits, which contained the serial number of a specific genre.

The various genres were numbered in the following way: G1 = Item Songs; G2 = Romantic genre; G3 = Rap/Outrageous; G4 = Sufi Genre; and G5 = Value-based Songs. Set Randomization method within the genres was used to nullify the practice effect and according to the order of the chits, songs for each genre were presented to them. Each song was played for a minute and they were asked to rate the thoughts, feelings and actions that were evoked on listening to that particular piece. Each participant had to rate 20 songs and they could leave their feedback (if they wished to) at the end of the survey.

\section{RESULTS}

On an average, $25.44 \%$ respondents were found above $75^{\text {th }}$ percentile who rated high on all three categories namely thought, feelings, and action after listening to songs from various music genres. Particularly for the genre 'Item', 31.67\% respondents rated the highest for feelings and only $13.33 \%$ respondents rated the least for thoughts.

Table 1: Preference ratings for thoughts, feelings and actions evoked from various genres

\begin{tabular}{lllll}
\hline \multirow{2}{*}{ Music Genres } & \multicolumn{4}{l}{ Perceived ratings } \\
\cline { 2 - 5 } G1 & T & N & M & SD \\
& F & 60 & 63.98 & 17.59 \\
& A & 60 & 50.90 & 9.52 \\
G2 & T & 60 & 60.63 & 15.65 \\
& F & 60 & 74.56 & 18.57 \\
& A & 60 & 65.03 & 12.97 \\
G3 & T & 60 & 62.63 & 15.21 \\
& F & 60 & 65.08 & 15.96 \\
& A & 60 & 47.65 & 7.79 \\
G4 & T & 60 & 60.97 & 10.84 \\
& F & 60 & 63.73 & 14.35 \\
& A & 60 & 58.01 & 10.23 \\
G5 & T & 60 & 53.27 & 9.94 \\
& F & 60 & 51.77 & 13.58 \\
& A & 60 & 52.75 & 10.98 \\
\hline
\end{tabular}

Table 1 lists ratings for different thoughts, feelings, and actions ( 4 = 'very much') evoked by various music genres. Ratings for thoughts evoked by genre 'Romantic' was the highest $(\mathrm{M}=74.56, \mathrm{SD}=18.57)$ which is followed by 'Rap', 'Item' and 'Sufi' genres. Feelings were evoked maximally $(M=65.03, S D=12.97)$ by the genre 'Romantic' and then by 'Sufi' genre 
( $\mathrm{M}=58.01, \mathrm{SD}=10.23)$. As far as actions are concerned, genres namely 'Romantic', 'Rap/Outrageous', and 'Item’ were respectively found more action evoking.

Table 2 indicates significant gender difference in terms of thoughts $\{t(58)=-2.545, p<.014\}$ evoked by Rap/Outrageous songs and feelings $\{t(58)=2.908, p<.005$ ) evoked by Value based songs. Moreover, from the table 2, it can be interpreted that Romantic songs evoked more amount of thoughts $(M=79.03, S D=16.64)$, feelings $(M=67.33, S D=12.11)$ and actions ( $\mathrm{M}=64.83, \mathrm{SD}=13.44)$; whereas, Rap/Outrageous as well as Sufi songs evoked more amount of thoughts $(M=70.10, S D=17.32 ; M=66.03, S D=13.22)$ in girls respectively. However, Value based songs produced more feelings $(\mathrm{M}=56.63, \mathrm{SD}=12.81)$ in boys as compared to girls.

Table 2: Means of thoughts, feelings and actions of each genre across genders.

\begin{tabular}{|c|c|c|c|c|c|c|}
\hline \multirow{3}{*}{$\begin{array}{l}\text { Genre wise Thoughts, } \\
\text { Feelings, and Actions }\end{array}$} & \multicolumn{4}{|c|}{ Gender } & \multirow[b]{3}{*}{$T$} & \multirow[b]{3}{*}{$\boldsymbol{P}$} \\
\hline & \multicolumn{2}{|l|}{ Boys } & \multicolumn{2}{|l|}{ Girls } & & \\
\hline & $\mathbf{M}$ & SD & $\mathbf{M}$ & SD & & \\
\hline G1_T & 64.13 & 20.21 & 63.83 & 14.87 & .065 & .948 \\
\hline G1_F & 51.67 & 11.26 & 50.13 & 7.50 & .620 & .537 \\
\hline G1_A & 60.90 & 19.01 & 60.37 & 11.68 & .131 & .896 \\
\hline G2_T & 70.10 & 19.58 & 79.03 & 16.64 & -1.904 & .062 \\
\hline G2_F & 62.73 & 13.59 & 67.33 & 12.11 & -1.384 & .172 \\
\hline G2_A & 60.43 & 16.74 & 64.83 & 13.44 & -1.123 & .266 \\
\hline G3_T & 60.07 & 12.91 & 70.10 & 17.32 & -2.545 & $.014^{* *}$ \\
\hline G3_F & 48.83 & 10.12 & 46.47 & 4.26 & 1.181 & .243 \\
\hline G3_A & 60.67 & 11.93 & 61.27 & 9.83 & -.213 & .832 \\
\hline G4_T & 61.43 & 15.27 & 66.03 & 13.22 & -1.247 & .217 \\
\hline G4_F & 58.63 & 11.58 & 57.40 & 8.81 & .464 & .644 \\
\hline G4_A & 53.63 & 10.18 & 52.90 & 9.85 & .283 & .778 \\
\hline G5_T & 50.57 & 14.88 & 52.97 & 12.27 & -.681 & .498 \\
\hline G5_F & 56.63 & 12.81 & 48.87 & 7.05 & 2.908 & $.005^{* *}$ \\
\hline G5_A & 50.03 & 9.36 & 47.73 & 8.33 & 1.006 & .319 \\
\hline
\end{tabular}

${ }^{*} p<.05,{ }^{* * *} p<.01$

Mean differences in terms of levels of education (UG/PG and Intermediate) are significant for all three categories namely thoughts $\{t(58)=-3.33, p<.002) ; t(58)=-2.32, p<.024\}$, feelings $\{t(58)$ $=-2.54, p<.014) ; t(58)=-2.94, p<.005\}$ and actions $\{t(58)=-2.87, p<.006) ; t(58)=-3.34$, $p<.001\}$ for genres Item and Rap/Outrageous respectively. (Table 3)

However, for genre Romantic, mean differences are significant only for thoughts $\{t(58)=-2.55$, $p<.013\}$ and actions $\{t(58)=-2.69, p<.009\}$. Moreover, across all music genres, except thoughts produced by Value based songs, it is apparent that Intermediate passed students perceived more 
thoughts, feelings and actions than UG/PG students after listening to songs of different genres. (Table 3)

Table 3: Showing the mean of thoughts, feelings and actions of each genre across level of education ( $\left.U G-n_{1}=21 ; P G-n_{2}=38\right)$.

\begin{tabular}{|c|c|c|c|c|c|c|}
\hline \multirow{3}{*}{$\begin{array}{l}\text { Genre wise Thoughts, } \\
\text { Feelings, and Actions }\end{array}$} & \multicolumn{4}{|c|}{ Level of Education } & \multirow[b]{3}{*}{$t$} & \multirow[b]{3}{*}{$p$} \\
\hline & \multicolumn{2}{|c|}{ UG/PG } & \multicolumn{2}{|c|}{ Intermediate } & & \\
\hline & $\mathbf{M}$ & SD & $\mathbf{M}$ & SD & & \\
\hline G1_T & 54.24 & 12.43 & 68.97 & 18.01 & -3.33 & $.002^{* *}$ \\
\hline G1_F & 46.67 & 6.67 & 52.92 & 10.11 & -2.54 & $.014^{* *}$ \\
\hline G1_A & 52.95 & 8.63 & 64.47 & 17.18 & -2.87 & $.006^{* *}$ \\
\hline G2_T & 66.52 & 18.54 & 78.95 & 17.54 & -2.55 & $.013^{* *}$ \\
\hline G2_F & 61.90 & 13.33 & 66.29 & 12.51 & -1.26 & .213 \\
\hline G2_A & 55.57 & 10.51 & 66.13 & 16.19 & -2.69 & $.009^{* *}$ \\
\hline G3_T & 58.71 & 11.99 & 68.50 & 17.13 & -2.32 & $.024^{*}$ \\
\hline G3_F & 43.81 & 5.66 & 49.71 & 8.16 & -2.94 & $.005^{* *}$ \\
\hline G3_A & 54.95 & 8.22 & 64.05 & 10.88 & -3.34 & $.001^{* *}$ \\
\hline G4_T & 59.38 & 12.98 & 66.05 & 14.86 & -1.72 & .090 \\
\hline G4_F & 54.52 & 8.74 & 59.71 & 10.65 & -1.90 & .062 \\
\hline G4_A & 50.09 & 9.09 & 54.63 & 9.97 & -1.73 & .090 \\
\hline G5_T & 53.76 & 13.62 & 50.47 & 13.72 & .88 & .381 \\
\hline G5_F & 51.28 & 9.88 & 53.53 & 11.73 & -.74 & .461 \\
\hline G5_A & 47.38 & 9.95 & 49.74 & 8.34 & -.92 & .363 \\
\hline
\end{tabular}

${ }^{*} p<.05,{ }^{* *} p<.01$

Thoughts evoked by Items songs were positively correlated with 'extraversion' personality factor, $r(60)=.298, p<.021$. Thoughts $(r(60)=.282, p<.029)$ and feelings $(r(60)=.341, p<$ .008) perceived while listening to Romantic songs were positively correlated with 'neuroticism', whereas, thoughts $(r(60)=-.302, p<.019)$ and feelings $(r(60)=-.289, p<.025)$ produced from Romantic songs were negatively correlated with 'conscientiousness.' (Table 4)

'Openness' and 'extraversion' were positively correlated with thoughts $\{r(60)=.328, p<.011$, $r(60)=.415, p<.001\}$ and feelings $\{r(60)=.289, p<.025, r(60)=.362, p<.004\}$ rated for genre 'Rap/Outrageous' respectively, while, 'conscientiousness' was negative correlated with thoughts, $r(60)=-.289, p<.025$, and actions, $r(60)=-.288, p<.026$. (Table 4) 
Table 4: Correlations between of thoughts, feelings and actions evoked by songs of various genres with five personality factors $(\mathrm{N}=60)$

\begin{tabular}{|c|c|c|c|c|c|c|}
\hline & & Openness & Extraversion & Agreeableness & Conscientiousness & Neuroticism \\
\hline & $r$ & .038 & $.298^{*}$ & -.095 & -.228 & .042 \\
\hline \multirow[t]{2}{*}{ G1_T } & $p$ & .771 & .021 & .472 & .079 & .749 \\
\hline & $\mathrm{r}$ & .126 & .235 & -.252 & -.243 & -.040 \\
\hline \multirow[t]{2}{*}{ G1_F } & $p$ & .336 & .071 & .052 & .062 & .763 \\
\hline & $\mathrm{r}$ & .014 & .230 & -.181 & -.253 & .151 \\
\hline \multirow[t]{2}{*}{ G1_A } & $p$ & .913 & .078 & .166 & .051 & .250 \\
\hline & $\mathrm{r}$ & .205 & .043 & .032 & $-.302^{*}$ & $.282^{*}$ \\
\hline \multirow[t]{2}{*}{ G2_T } & $p$ & .116 & .743 & .810 & .019 & .029 \\
\hline & $r$ & .170 & -.053 & -.109 & $-.289^{*}$ & .253 \\
\hline \multirow[t]{2}{*}{ G2_F } & $p$ & .194 & .686 & .408 & .025 & .051 \\
\hline & $r$ & .116 & -.038 & -.066 & -.251 & $.341^{* *}$ \\
\hline \multirow[t]{2}{*}{ G2_A } & $p$ & .377 & .774 & .616 & .053 & .008 \\
\hline & $r$ & $.328^{*}$ & $.415^{* *}$ & .193 & -.009 & .038 \\
\hline \multirow[t]{2}{*}{ G3_T } & $p$ & .011 & .001 & .139 & .943 & .771 \\
\hline & $r$ & .069 & .134 & -.232 & $-.289^{*}$ & .154 \\
\hline \multirow[t]{2}{*}{ G3_F } & $p$ & .602 & .308 & .075 & .025 & .241 \\
\hline & $r$ & $.289^{*}$ & $.362^{* *}$ & -.094 & $-.288^{*}$ & .170 \\
\hline \multirow[t]{2}{*}{ G3_A } & $p$ & .025 & .004 & .475 & .026 & .193 \\
\hline & $r$ & .200 & -.079 & .039 & -.250 & $.335^{* *}$ \\
\hline \multirow[t]{2}{*}{ G4_T } & $p$ & .126 & .548 & .765 & .054 & .009 \\
\hline & $r$ & .195 & -.124 & -.128 & $-.361^{* *}$ & .207 \\
\hline \multirow[t]{2}{*}{ G4_F } & $p$ & .135 & .345 & .331 & .005 & .113 \\
\hline & $r$ & .118 & -.079 & -.017 & -.122 & .218 \\
\hline \multirow[t]{2}{*}{ G4_A } & $p$ & .367 & .550 & .900 & .351 & .095 \\
\hline & $r$ & .076 & .040 & .072 & .189 & .018 \\
\hline \multirow[t]{2}{*}{ G5_T } & $p$ & .566 & .760 & .585 & .147 & .893 \\
\hline & $r$ & -.155 & -.134 & $-.276^{*}$ & -.007 & .110 \\
\hline \multirow[t]{2}{*}{ G5_F } & $p$ & .236 & .309 & .033 & .956 & .401 \\
\hline & $r$ & -.035 & .084 & .011 & .130 & -.012 \\
\hline G5_A & $p$ & .788 & .525 & .936 & .323 & .929 \\
\hline
\end{tabular}

** Correlation is significant at the 0.01 level (2-tailed).

* Correlation is significant at the 0.05 level (2-tailed).

Feelings, $r(60)=-.361, p<.005$, evoked by Sufi songs were negatively correlated with 'conscientiousness' whereas thoughts, $r(60)=.335, p<.009$, were positively correlated with 'neuroticism.' As far as Value based songs were concerned, feelings, $r(60)=-.276, p<.033$, generated were negatively correlated with 'agreeableness.' (Table 4) 


\section{DISCUSSION}

Present study explored the effect of songs (with lyrics) from various music genres on young adults' thoughts, feelings, and actions irrespective of their gender and their levels of education and the ratings on these three variables. It further examined the correlations of personality factors with thoughts, feelings, and actions across music genres.

Results indicated that, in general, each and every song representing any of the genres taken up in this study evoked significant amount of thoughts, feelings, and action in its listeners. Particularly, Romantic songs were found the most significant genre which evoked maximum thoughts, feelings, and action tendencies. It can be derived that Romantic genre cuts across all as the mean of thoughts, feelings and actions and the variability of scores were the highest for this genre. It is evident that young adults, of today, get easily connected to this genre.

Talking about the gender differences, it was found that except feelings (generated through Value based songs which is more in boys as per their Mean), the amount of thoughts, feelings and action tendencies perceived for Romantic songs and amount of thoughts reported for genres namely Rap/Outrageous and Sufi were higher (referring Mean values) in girls respondents in comparison to boys. Across, all the genres it could be seen that girls experienced a greater cognitive and conative impact as compared to boys on being exposed to various genres of music. This may be because women are more likely to respond to music emotionally and on being exposed to different types of songs, there was an instant evocation of thoughts which led to experience of certain emotions (Chamorro-Premuzic, 2009).

Across all music genres, except thoughts produced by Value based songs, it is apparent that Intermediate passed students perceived more thoughts, feelings and actions than UG/PG students after listening to songs of different genres. It can be inferred that different music genres had greater impact on the respondents who had just completed their intermediate degrees rather than those who completed their graduate and post-graduate degrees.

Thoughts evoked by Items songs were positively correlated with 'extraversion' personality factor. This genre has fast rhythm and pace and therefore, people who are energetic and enthusiastic enjoyed this Genre the most (Rentfrow \& Gosling, 2007).

Thoughts and feelings perceived while listening to Romantic songs were positively correlated with 'neuroticism', whereas, thoughts produced from Romantic songs were negatively correlated with 'conscientiousness.' Research suggest that people who are shy, moody and have low cortical level easily got affected and experienced elevated emotions and thoughts on hearing romantic pieces as the people who are high on neuroticism uses music for emotional regulation whereas, Conscientiousness did not predict use of music for emotional regulation (ChamorroPremuzic \& Furnham, 2007). 
'Openness' and 'extraversion' were positively correlated with thoughts and feelings rated for genre 'Rap/Outrageous' respectively, while, 'conscientiousness' was negative correlated with thoughts and actions. The extraverts usually have a preference for energetic and rhythmic music as they are extremely confident, bold and attractive in nature and the people who are high on openness to experiences prefer music that are reflexive and complex because they are openminded, politically liberal, creative, intelligent, tolerant and enjoys aesthetic experiences. However, people who are upbeat and conventional (high on conscientiousness) are politically more conservative and do not enjoy songs that are against the society or norms (Rentfrow \& Gosling, 2003).

Feelings evoked by Sufi songs were negatively correlated with 'conscientiousness' whereas thoughts were positively correlated with 'neuroticism.' As far as Value based songs were concerned, feelings generated were negatively correlated with 'agreeableness.' The Sufi songs have an emotional connect with the listeners because of its soulful rhythm and music and therefore, neurotics, as previously specified, uses music for emotional regulation. These songs also outlines around the religious duties of mankind and therefore, it becomes easier for the people who are high on conscientiousness to connect to it.

People who are high on agreeableness usually have higher emotional responses to music provided they have previous musical training. Therefore, they couldn't connect to these types of songs because the young adults, nowadays, are not exposed to these songs and it was extremely unconventional for them (Robazza et al., 1994).

\section{CONCLUSION}

This study provides insights about the significance of music as media in day-to-day lives of young adults, particularly on their cognition and the amount of affect based on their personality factors. The time phrase [young adulthood] embraces what has been called the most crucial age which range for the creation of a distinctive and self-conscious generation (Jennings \& Niemi, 1981), needs to be exposed to such music which not only proves to be a source of chills and enjoyment but also which may foster well-being.

Due to paucity of time, the sample size was restricted to only 60 participants only. The paper was also limited to only finding out the impact of various music genres on the thoughts, feelings and actions of the young adults. The dominant thought, feeling or action for each genre could not be derived. The research was done using only five genres out of various music genres due to time constraints. Including many other genres might throw light on a different dimension altogether. Whether previous music training had any significant contribution in evoking thoughts, feelings and actions also could not be studied. 


\section{REFERENCES}

Bushman, B.J., \& Anderson, C.A. (2002). Violent video games and hostile expectations: A test of the general aggression model. Personality and Social Psychology Bulletin, 28(12), 1679-1686.

Chamorro-Premuzic, T. G., \& Furnham, A. (2007). Personality and Music: Can Traits explain how people use music in everyday life? British Journal of Psychology, 98(2), 175-185.

Chamorro-Premuzic, T. G., Gomà-i-Freixanet, M., Furnham, A., \& Muro, A. (2009). Personality, self-estimated intelligence, and uses of music: A Spanish replication and extension using structural equation modeling. Psychology of Aesthetics, Creativity, and the Arts 3(3), 149-155.

Fischer, P. \& Greitemeyer, T. (2006). Music and aggression: the impact of sexual-aggressive song lyrics on aggression-related thoughts, emotions, and behaviour toward the same and opposite sex. Personality and Social Psychology Bulletin, 32(9), 1165-76.

Frey, W. H. (1985). Crying: The mystery of tears. Minneapolis, MN: Winston Press.

Goldberg, L. R. (1993). The structure of phenotypic personality traits. American Psychologists, 48(1), 26-34.

Hargreaves, D. J., \& North, A. C. (2010). Experimental aesthetics and liking for music. In P. N. Juslin and J. A. Sloboda (Eds.), The handbook of music and emotion: Theory, research, applications (pp. 515-546). Oxford, UK: Oxford University Press.

Jacob, C., Gueguen, N., Boulbry, G., \& Sami, S. (2009). Love is in the air: congruence between background music and goods in a florist. The International Review of Retail, Distribution and Consumer Research, 19(1), 75-79.

Jennings, M. K., \& Niemi, R. G. (1981). Generation and politics. Princeton, N. J.: Princeton University Press.

John, O.P., \& Srivastava, S. (1999). The big-five trait taxonomy: history, measurement, and theoretical perspectives. In L.A. Pervin \& O.P. John (Eds.), Handbook of Personality: Theory and Research (2nd ed.). New York: Guilford Press.

Juslin P. N., Sloboda J. A. (eds) (2001). Music and Emotion: Theory and Research. Oxford: Oxford University Press

Kivy, P. (1989). Sound Sentiment: An Essay on the Musical Emotions, Including the Complete Text of the Corded Shell. Temple University Press.

McCown, W., Keiser, R., Mulhearn, S., \& Williamson, D. (1997). The role of personality and gender in preference for exaggerated bass in music.Personal Individual Differences, 23(4), 543-547.

Rawlings, D. \& Ciancarelli, V. (1997). Music Preference and the Five-Factor Model of the NEO Personality Inventory. Psychology of Music, 25(2), 120-132.

Rentfrow, P. J., \& Gosling, S. D. (2007). The content and validity of music-genre stereotypes among college students. Psychology of Music, 35, 306 -326.

Rentfrow, P.J. \& Gosling, S.D. (2003). The Do Re Mi's of everyday life: The structure and personality correlates of music preferences. Journal of Personality and Social Psychology, 84(6), 1236-1256.

Robazza, C., Macaluso, C. \& D’Usro V. (1994). Emotional reactions to music by gender, age and expertise. Perceptual and Motor Skills 79(2), 939-944.

Zentner, M \& Eerola, T. (2010). Rhythmic engagement with music in infancy. Retrieved from http://www.pnas.org/content/107/13/5768.abstract on 02/02/2015 